Temporal events and problem structuring

Luke Houghton (Corresponding Author)

Griffith University

Nathan QLD 4111

Ph: +61 37357721

Fax: +61 737355111

l.houghton@griffith.edu.au

Larry Crump

Griffith University

Nathan QLD 4111

l.crump@griffith.edu.au 


\title{
Temporal Events and Problem Structuring
}

\begin{abstract}
Problems come with a history and sometimes an assumed future. Our understanding of the past and our assumptions of the future shape the way we structure problems. In this paper we explore how the past and the future might influence temporality in problem structuring and identify the utility of linkage theory in providing temporal understanding. Data for this paper are derived from trade treaty negotiations conducted by the United States and Singapore (2000-03), Australia and Singapore (2000-03), and Australia and the United States (200304). These three negotiations, occurring concurrently or consecutively in time, allow us to examine a temporal quality to problem-structuring through linkage theory. This study enriches our understanding of the problem-structuring methods (PSM) literature by focusing on how temporal issues play a role in how problems are structured. The negotiation context described above is used as an exemplar of how temporal issues affect problem structuring. Our aim is to begin a discussion on how and if a temporal perspective can be handled methodologically.
\end{abstract}

Keywords: Problem structuring, soft OR, problem-structuring methods, linkage theory, temporal forces 


\section{Introduction}

Over the past few decades, the emergence of soft operations research (soft OR) has given rise to the development of problem-structuring methods (PSMs) (Mingers and Rosenhead, 2004). The PSM tradition in soft OR is a practically focused collection of methodologies that assist (Eden and Ackermann, 2006) structuring ill-defined problem context (Franco 2009) with the purpose of working towards agreed feasible change (Checkland, 1999; Huaxia, 2010). A PSM often facilitates accommodation for difficult problems (Ackermann and Eden, 2011b; Houghton, 2012), shifts boundaries to create systemic change (Ulrich, 2003), discovers alternative strategic options (Friend and Hickling, 1987) and fosters critical perspectives (Gregory 2009), while addressing many other concerns (Mingers, 2011). A core aim of PSM is to find meaning in order to help organize thinking about messy problems (Checkland, 2005).

PSM research generally is interventionist (Midgley and Ochia-Rias, 2004) in nature, as it is often focused on how to structure meaning from difficult situations, ranging from large-scale negotiations (Cushman et al., 2006; Franco, 2008, 2009) and complex strategymaking (Burt, 2011) to conservation planning (Larsen, 2011) and other related issues (see Mingers and Rosenhead, 2004). As part of this development, researchers have begun to explore the political and historical context of a problem as one part of the problem structuring intervention. It has been established and argued for a few decades that the history of a problem the history of a problem, its politics and individual framing are part of the dynamics of building a strategic agenda (Jackson 1983, Checkland and Scholes, 1985, Eden 1987, Rosenhead, 1989, Rosenhead, 1996, Jackson 2001, Franco, Shaw \& Westcombe 2007 for example). This answers a question put to researchers by Rosenhead (2006), who argued that PSMs should consider larger, more complex contexts so as to grow beyond the managerialist, 
small-group agenda (somewhat answered in the work of Franco 2006:2007). The question becomes how do those contexts influence problems whilst they are being structured?

PSM research specifies a certain 'dynamic' environment where the connections between the actors in a problem structuring exercise are well determined, often contemporaneous and moulded to a specific type of organisational context (Ulrich 2003). For example, in Strategic and Development Options Analysis (SODA), the connections between the dynamic aspects of problem linkages are explored. In drama theory (Bryant, 2007), the idea of connections - particularly in negotiations-is explored in some depth. We also see more connections in systems dynamics with group model-building, a methodology that explores how actors influence each other in a group environment (Vennix, 1999). History, politics (Jackson, 2001) and individual conceptions of a problem, including the 'dynamic linkages' between actors in a present context, are well established within the PSM literature (see also Ackermann and Eden, 2011a). Even more recently, the connections between ‘events’ and 'structural outcomes’ in interventions have been explored from a linkage perspective (Howick et al., 2011). This has opened up the idea that problem structuring occurs in a dynamic connected environment (Bryant, 2004), where linkages between different parts of a problem are explored (Ackermann and Eden 2011a).

While these discussions about the role of politics and history are important, what has not been explored in depth is the role of 'temporal' issues in determining a problem's context. While researchers have explored this as an issue (see Bryant 2007; Eden and Ackerman, 1998; Ackerman and Eden, 2011b for examples), the role of previous events—and even the anticipation of future events—-have not been explored as being theoretically or methodologically relevant to the problem's context. A problems context is often layered with political realities. This was a criticism of the Soft OR literature early on (see Jackson 1983, Checkland, 1985) as it was believed that SSM (Soft Systems Methodology) in particular, was 
not equipped to manage political issues. While a host of methodologies in the critical systems thinking area are tackling the present political issues, what about the previous decisions made or perceptions of future events?

These issues are important for two main reasons. Firstly, these decisions were made at a specific time with a specific 'frame' for the future. This means that decisions are often made with an implied context for the future in mind. While the critical systems literature deals with the present context and to a limited extent the past, it fails to demonstrate how the underlying temporal context can guide and structure the future through actor perceptions. In this paper we wish to demonstrate how this implied context for the future shapes and drives problem structuring in the present. It is thought that this exploration will enhance PSM interventions because it demonstrates how perceptions of time play a role in structuring complex issues.

A temporal context may add depth to a problem structuring intervention because it will allow the modeller/analyst to explore the role of previous decisions and explore the perception of future events on current problem interaction process. For example, one such event may be an intervention where assumptions about the future have been made and these assumptions play the role of 'guiding' the analyst to certain outcomes. The process of guiding here refers to the role of perceived future events in shaping current problem interaction processes, and the role of past events in shaping current problem interaction processes. The purpose of this paper is to explore an exemplar of temporal issues to see what kind of impact they have on problem structuring in a negotiation context. Although this is not a contribution to the negotiation literature, it provides an exemplar that future research can build on for understanding temporal issues in problem structuring. This leads us to the primary aim and research question of this article: What impact do temporal events play in problem structuring interventions? 
We recognise that dynamic linkages in the present (concurrent linkages) are covered extensively within the PSM literature (see Eden and Ackermann, 1998 for one prominent example). However, the idea that the past can influence the present through previous interventions, by controlling the parameters of an intervention, has not been explored adequately. To investigate this, we examine a series of negotiations to learn what role temporal events play in structuring problems. We introduce linkage theory and examine a series of events where prior decisions influence and shape contemporary decisions consecutively. The exemplar provided is designed to promote discussion around what might a PSM model look like when seeking to include temporal solutions. We also examine the possibility that future expectations might have an impact on contemporary decision-making. This article examines how both the past and expectations of the future (consecutive linkage) shape problem structuring.

This is an exploratory study, so it would be premature to seek to develop a new methodology. Rather, we seek to demonstrate how linkage theory can be used to understand the role of temporal forces within problem structuring and to establish the qualities within these forces that may shape outcomes. We argue that, while existing PSM studies point out the problem of history (a consecutive linkage to the present) and concurrent contexts (linked but unrelated events occurring simultaneously), we do not have an adequate toolkit to explore these issue and their implications. As such, we are using linkage theory to create a context for understanding how past and future events impact upon contemporary decision-making processes. The current study considers the role of the past and the perceived future in problem structuring. We sought answers to two hypotheses: (1) What role does the past play in problem structuring and (2) What role does the perceived future play in problem structuring. Given the exploratory nature of this study we sought to keep an open mind by not seeking to further structure data gathering processes. 
In the following section, we introduce linkage theory and then present two case studies where these temporal issues are explored. Our aim is to facilitate a discussion on future research about including a temporal perspective as one part of existing problem structuring methodologies. Our challenge to the literature is: How can we, as problem finishers (Eden, 1987), recognise and manage temporal issues?

\section{Background: Review of Linkage Theory Literature}

Linkage theory was first developed through the field of international relations, although negotiation study further developed our fundamental understanding of linkage theory. 'The politics of many international negotiations can usefully be conceived as a two-level game.' (Putnam, 1988: 434) This metaphor inspired substantial research in developing a methodology to examine the relationship between domestic politics and international relations. For example, studies use Putnam's two-level theory to examine links between domestic politics and regional integration (Huelshoff, 1994) and to demonstrate how "issue linkage” makes it possible for national leaders to adopt international policy decisions over the protests of influential domestic lobbies (Davis, 2004).

The study of issue linkage precedes the two-level games literature. "Issue linkage” is a negotiating device for making trades among diverse issues within a single negotiation or between separate but linked negotiations involving the same parties. Jensen (1963) was the first to document issue linkage in his study of negotiations between the United States and the Soviet Union concerning nuclear arms. Other subsequent studies examine the forces motivating parties to engage in linkage (Tollison and Willett, 1979), strategic choices in employing linkage (Keohane and Nye 1989) and related matters. Li (1993) concludes that issue linkage is a widespread practice in international relations, and Odell (2000) observes that issue linkage is found in every negotiation except those that consider only a single issue. 
Path dependency grows out of a temporal tradition within the international relations literature. Path dependency means that current and future actions, decisions or states depend on the path of previous actions, decisions or states (Page 2006). Preceding steps in a particular direction induce further moment in the same direction (Pierson 2000), with increasingly constrained processes that cannot be escaped (Vergne and Durand 2010). "History matters” (David 1994).

Linkages between structural levels (e.g. domestic and international), issues (e.g. linking market access in agriculture to market access in manufactured goods) and path dependency (i.e, history matters) are the three most common way of understanding linkage theory within the international relations literature.

Game theory also has a long tradition of examining linkage dynamics. The Prisoners’ Dilemma game, for example, has studied the outcomes of single-issue negotiations conducted repetitively by the same parties. Such studies used consecutively linkages to demonstrate the conditions under which cooperation between parties is rational because linkages operate in a tit-for-tat manner (Taylor 1976; Axelrod 1984). McGinnis (1986) extends this work by conducting multiple games concurrently and consecutively to demonstrate the conditions under which cooperation between parties is rational in linages that operate in a quid pro quo manner.

Within the study of negotiation, the most prominent type of linkage involves a negotiation and its discrete alternative. In this fifth linkage class, problem structuring is grounded in competitively linked dynamics. A best alternative to a negotiated agreement (BATNA) (Fisher and Ury, 1981) can increase or decrease negotiation power (Lax and Sebenius, 1986; Raiffa, 1982).

A sixth and final linkage class involves temporal linkage dynamics, or the use of a temporal framework when engaging in problem-structuring methodology. 'Consecutive linkage' and 'concurrent linkage' as introduced above in game theory, constitute the primary temporal framework for understanding this final class of linkage dynamics. The relationship 
between past, present and future (i.e. temporal logic) is well established in the study of negotiation and management (Ancona et al., 2001), although little is known about how present negotiations are used to influence perceived future negotiations. Agreeing initially on a general framework to guide future negotiations (Mouzas, 2006), precedent-building (Hughes et al. 2012) and forum-shifting in seeking advantage (Drahos, 2007) have all been identified as strategic techniques that link the present to the future. The future is unknown, but the perceived future can impact upon our understanding of a problem, and so problem-structuring methodology that takes the perceived future into consideration has utility. Understanding how the past influences the present is less complex than understanding the relationship between the present and the perceived future.

All of these elements of linkage theory have application to structuring problems. The preceding discussion offers a foundation for future work. In this study we wish to examine linkage theory and temporal logic by focusing on a set of consecutive link events. Temporal logic is focused on the relationship between present and past (consecutive-past linkages) and present and future (consecutive-future linkages) will provide the theoretical framework to examine the relevance of consecutive linkage theory to PSM. What follows demonstrates the problem Rosenhead (2006) raises about structuring the extraordinary complexity of a large problem with multiple actors that have a past and a perceived future, while taking action in the present. This analysis is supported by a series of case studies that use linkage theory to structure and explain how key actors were engaged in complex organizational processes. It should be noted at this point that we are not suggesting this assumes a linear causality. Linkage theory is simple used as a way to explore the influence of temporality on problem structuring. Linkage theory is a framing device not a tool that consistently captures causality although sometime causality maybe inferred given the facts through a linkage framework. 
Finally, it is important to note that the methodology for this paper has evolved over a number of studies found within the negotiation literature. The case methodology section that follows draws on earlier studies found within the negotiation literature (see Crump, 2010) although this earlier study was focused on concurrent linkage dynamics (occurring at the same time) our article is concerned with consecutive linkage dynamics (occurring one after another: past to present, present to future). In addition, another earlier study (also found in the negotiation literature) examines temporal linkage dynamics (Crump, 2007), which is the focus of the current paper although the conclusions for our paper are directed toward operations research generally and problem structuring specifically.

\section{Case Methodology}

This section outlines case construction, data sources and data-analysis methods. First, it is important to recognize that the methods used to study linkage dynamics are not the same methods that will be used by PSM practitioners to gain temporal understand. Temporal understanding is gained when parties (e.g., clients) are repetitively engaged in the same activities or set of activities with other parties. Linkages occur over time (past and perceived future) when the same parties continually interact in the same context, which is often the result of repetitive behavior (which is a consequence of specialization).

This section addresses the question of studying linkage dynamics rather than gaining temporal understanding through linkage theory. We employed a multiple-case design with a structured focused case-comparison approach. Analysis from a multiple-case design can strengthen (substantiate or refute) observations arrived at through analysis of each individual case (Druckman, 2005; Yin, 1989). We also used a qualitative embedded design that includes three levels of analysis (Eisenhardt, 1989) by examination of: (1) a single negotiation; (2) linkage dynamics between negotiations or within a single case; and (3) cross-case analysis. 
Specific negotiations were selected because it appeared that they may contain linkage dynamics.

Data are derived from three joint-decision problems or free trade negotiations involving (1) Singapore and Australia, (2) the United States and Singapore and (3) Australia and the United States. It is important to note that each negotiation is treated as data, not as a case in the present study, as the interaction or linkage between negotiations is the primary unit of analysis in this study. As such, linkage dynamics or behaviour connecting two negotiations are treated as cases in the present study. Figure 1 provides a process overview and a visual image of each negotiation by presenting a timeline that depicts the structural relationship for our case studies.

Insert Figure 1 about here

Temporal logic requires that attention be given to the timing or dates of critical negotiation moments (Mitchell and James, 2001), such as when group process or negotiations actually begin and conclude. Figure 1 portrays temporal process and linkage structure for negotiations that concluded the Singapore-Australia Free Trade Agreement (SAFTA) of 2003, the United States-Singapore Free Trade Agreement (USSFTA) of 2003 and the Australia-United States Free Trade Agreement (AUSFTA) of 2004. Case data indicate that AUSFTA began after SAFTA and USSFTA negotiations were substantially concluded: SAFTA concluded in October 2002, USSFTA concluded in January 2003, and AUSFTA negotiations began in March 2003. Thus temporal logic indicates that AUSFTA was initially consecutively future-linked to SAFTA and USSFTA because data (reviewed later in this article) indicate that there was a clear expectation that AUSFTA negotiations would commence while SAFTA and USSFTA negotiations were occurring. However, by the time the AUSFTA negotiation began, SAFTA and USSFTA had finished and so the first two 
negotiations became consecutively past-linked to the third. Figure 2 establishes consecutive linkage structure for these three negotiations.

Insert Figure 2 about here

It is useful to note that the forces that create consecutive future action and those that create consecutive past action are not exactly the same. Expectations or predictions of the future are inherently subjective (thus the broken line connecting expectations of the future to the present in Figure 2), and often generate debate and disagreement. Our understanding of the past, however, is much more certain than our predictions of the future (thus the solid line linking the record of the past to the present). When examining past linkages, we have historical fact available for interpretation, but when examining future linkages, actions generated in the present rely on expectations or projections of a likely future. Generally, the further into the future, the more difficult it is to rely on such expectations and projections.

\subsection{Data Sources}

Data collection began through searching electronic archives on the official website of each national government in order to download many relevant documents. Field research through face-to-face interviews facilitated the collection of additional documents (see Odell, 2006). We conducted 86 formal interviews with trade negotiators, trade policy specialists, diplomats and ambassadors involved in these three negotiations. Although not all of those interviewed were directly involved, all were very knowledgeable about the negotiations. For example, a nation's ambassador or embassy staff would not normally sit at the negotiation table, as they would have other duties, but they would also be very knowledge about these negotiations. Field 
research was conducted at four sites: Canberra, Geneva, Singapore and Washington, DC. Fieldwork was conducted in 2004 under the following research schedule:

- 2-6 February Canberra

- 2-5 March Canberra

- 15 - 19 March $\quad$ Singapore

- 6-7 April Geneva

- $12-22$ April Singapore

- 1-18 June Washington DC

- $19-23$ July Canberra

Interviews were secured through the power of relational practice (Dutton and Dukerich, 2006), including snowballing techniques. A national negotiation team includes a chief negotiator and between 30 and 100 government officials (negotiators) in any given bilateral trade negotiation. Chief negotiators are executive-level managers and strategists for their respective governments. Each team is normally organized into between fifteen and twenty issue-focused groups (e.g. goods, services, financial services, investment, telecommunications, electronic commerce, intellectual property, labour, environment, etc.), usually one group per treaty chapter. Interviews were sought with anyone directly involved in the negotiation plus relevant embassy staff. Interviews were semi-structured and began with questions about a respondent's role in a negotiation. If respondents were involved in more than one negotiation of empirical interest, then each negotiation was considered separately. Interviews lasted between 60 and 90 minutes.

\subsection{Data Analysis}

Using a structured focused comparison approach, we were able to impose the logic of experimentation on a small number of cases. Multiple cases provide a more dynamic basis for 
theory building, as multiple-case methodology enables comparison between cases and broader exploration of the research question and theory elaboration (Eisenhardt and Graebner, 2007).

After documenting the negotiation process and outcome for each case, we applied pattern-matching analytical procedures to determine linkage categories or domains within each case. The purpose of this procedure was to build a plausible—although provisional— explanation for the linkage events identified in the three cases or experiments as a way to identify and explain causal relationships. A cross-case comparison was also conducted to strengthen the validity of such explanations (Druckman, 2005; Yin, 1989).

Data were analysed at three levels to establish content validity. Interview and archival data were evaluated for consistency (1) within each negotiation side, (2) between sides engaged in a negotiation and (3) between linked negotiations comprising a single case. If a contradiction was identified at any level of analysis, all data relevant to a contradiction were discarded from the results. Interview notes, field observations and relevant documents were separated into (1) data concerning negotiation process and outcome for three negotiations, (2) data demonstrating linkage events based on interaction between two negotiations and (3) data for a structured focused comparative analysis between two cases. This procedure is consistent with research protocol relevant to within-case analysis and cross-case analysis (Druckman, 2005; Eisenhardt, 1989).

First, summaries of each negotiation were prepared to gain an overall understanding of the negotiation process and outcome. Data indicating the fundamental characteristics of each negotiation were extracted from these summaries and organized in tabular form.

Insert Table 1 about here 
Second, data relevant to negotiation linkage dynamics were identified through pattern-matching logic. Based on results of our preliminary analysis, linkage domains or event-categories were identified that provided a foundation for organizing these data in narrative form into a matrix of linkage event-categories. Iteration between data and plausible causal explanations for each of these linkage event-categories occurred throughout the analysis (Eisenhardt, 1989; Yin, 1989). Present-past and present-future (temporal) theory was the primary conceptual structure applied at this phase of analysis, as group process within these negotiations were consecutively structured. Third, event-categories that appeared across two or more cases were identified using structured focused cross-case analysis. This process strengthened the plausible causal explanations developed in the second phase of analysis (Druckman, 2005).

Case observations, analysis, theory and practice implications are considered in each part, as this approach represents best practice for presentation of empirical findings in multicase studies (Eisenhardt and Graebner, 2007). Through this review, we seek to shed light on PSM dynamics when large groups and multiple small groups structure a problem while simultaneously being confronted with external events that occur in the past or future.

\section{Case Data and Analysis}

Problem structuring opportunities occur in many organizational environments, which require theory that supports problem structuring methods that is sufficiently flexible to accommodate such diversity. One problem structuring environment, not often studied, is the engagement of nations in the development of bilateral treaties through negotiation. The study that follows examines problem structuring in this setting from a temporal perspective.

Consecutive linkages are concerned with past and future. How is the past used strategically? How do negotiations or events from the past constrain or facilitate the current negotiation process and outcome? How might perception of a future negotiation or events 
constrain or facilitate the present negotiation process and outcome? How can a negotiation be conducted to gain strategic advantage in a perceived future negotiation? How do such questions establish a foundation for problem definition? Answers to these questions are found in the section that follows.

\section{Consecutive-Past Linkage: Present to Past}

Our fieldwork data support the view that current group process engaged in problem structuring can be influenced by the mere existence of a preceding linked negotiation or event. If there has been a prior relevant group process or negotiation for one side or the other, it is more likely that the side with this prior experience will present its position or problem structure all at once. In trade negotiations, this is in the form of 'preferred text', while this approach can appear as a demand or firm position, which can result in positional bargaining.

If there has been no prior group process negotiation or preceding linkage to draw upon, then the preferred text or problem structure will more likely evolve or be put forward in 'bits and pieces'. A problem structure produced over time will likely be informed by dialogue between the parties, and may appear to be developed through collaborative processes.

For example, before commencing negotiations with Singapore, the United States had not negotiated a substantial free trade agreement since the North American Free Trade Agreement (NAFTA) in 1994. Interview data indicate that since NAFTA, inter-agency trade debate within the US government had raged on several issues, including investment and the environment. Data also indicate that Singapore served as the venue that helped the US government to establish inter-agency consensus on issues such as competition policy, electronic commerce, financial services, government procurement, investment and telecommunications. The text or problem structure that eventually became the language of the USSFTA treaty appeared to be generated through collaborative processes, since the US 
team did not present its written position to Singapore all at once. However, by the time the United States began negotiating with Australia, it had built its inter-agency consensus, tested it through discussions in Singapore, was aware of what it wanted, and so presented its demands or problem structure to Australia as a package. For example, one Australian telecommunications negotiator reported surprise when his US counterpart sent him model text, as they had agreed in their first discussion to initially conduct a joint review of USSFTA and SAFTA text. When questioned, his US counterpart said that, regardless of any analysis of prior treaties, the text sent was the preferred US language and the US negotiator thought it better to provide this text up front rather than later on.

USSFTA and AUSFTA negotiations generally followed different processes. The absence of a relevant preceding linked negotiation in USSFTA talks and the presence of a preceding linked negotiation in AUSFTA talks help to explain differences in US negotiation behaviour with Singapore and Australia.

Insert Figure 3 about here

For linkage analysis and problem structuring, this means that connections may have a contextual reference point that needs to be carefully considered. Conclusions from this observation suggest that the framework an actor adopts, and the strategies employed in a collaborative problem-structuring process, may be influenced through prior relevant experience. This presents a challenge, in that most problem-structuring methods are interventionist by nature. Without reopening the debate about interventionist methodologies in problem structuring (see Ulrich, 2003), we merely wish to point out that consecutive linkage theory recognizes and includes the contextual history of the problem, and provides a basis for analytical insight for problem structuring (prior relevant experience vs. no prior 
relevant experience and the substantial impact this difference has upon group process and group dynamics).

The other issue is that the person modelling linkages may find that they are presenting data from their own context. Can an objective evaluation of linkages be gained from someone who holds an advantage or disadvantage within a specific context? In the cases presented here, the researcher was not involved in the negotiation, but observed and recorded interviews to gain insights needed to arrive at analytical conclusions. We note how specific political advantage plays a role in the way problem structuring takes place. History is a political reference point that frames the outcome of future debates because of key arguments and decisions already in place. Thinking about it in Ulrich’s (2003) terms, the discourse used to set boundaries for arguments is framed by those with the political power and timing to create certain desirable outcomes and certain problem interpretations.

Fieldwork data also indicate that group dynamics and a pattern of 'resistance, learning and acceptance' can appear across two or more consecutively linked negotiations (see Figure 4). For example, Singapore’s efforts to convince Australia to adopt a 'transformation system' as the primary test to determine product origin (where a product is actually produced) was unsuccessful, but the idea was introduced to Australia via SAFTA. When the United States proposed the same method, Australia accepted it in AUSFTA. Since then, Australia and New Zealand have held talks to modify their 1983 trade treaty to include a transformation system (Australian-New Zealand 2009).

Insert Figure 4 about here 
How do parties move from resistance to learning to acceptance? This is a fundamental issue within problem structuring that often ends with the idea of accepting an agreed definition to 'finish' the problem (Eden, 1987; Fisher and Ury, 1981; Conklin, 2005). Not much research has been done on how people actually come to accept problems and learn to live with certain problem interpretations from the perspective of soft OR. We argue that interpreting problems through consecutive linkage dynamics may offer one explanation or pattern for movement from resistance to learning to acceptance. More research should be focused on the relationship between consecutive linkage dynamics and the resistancelearning-acceptance pattern in the context of problem structuring.

Understanding how past events specifically influence a negotiation can provide some control over the present. It is also useful to consider how a group member or negotiator can use past events to strategically influence the current negotiation process and outcome. Knowledge of how the other side negotiated in the past can be used by group members to empower themselves at the negotiation table. Negotiators in Australia, Singapore and the United States all identified the importance of studying trade treaties or outcomes already concluded by the parties with whom they expected to negotiate. Sometimes motives can be inferred by examining changes in the text of several treaties involving the same party. Such observations can be used strategically in a competitive group process such as a negotiation, but these observations can also be used to understand how a particular group member frames a problem in the move towards problem structuring.

What this study adds is a theoretical framework through a temporal approach to past linkage theory and the idea that a problem-structuring process exists within a historical framework that provides the basis for what will be considered a mutually acceptable problem frame at some point in the future. It demonstrates that in larger and more connected problem situations, interventions by actors will be in part determined by earlier actions. By drawing 
out these consecutive-past linkages, we observe connections to previous decisions and agreements, which support the role that group members play in shaping problem-structuring outcomes. Interestingly, as the problem progresses, certain interpretations appear more obvious than others, which can contribute to 'feasible' solutions that are derived from historical problem interpretations. Problem interventions can often be examined through the previous engagements of powerful group members with similar problem situations. By looking at the activities of group members in this way, we are able to see how previous problem definitions affect those in the future by becoming the interpretative foundation for structuring problems.

Second, PSM literature traditionally focuses on the role of the analyst as 'intervening' in organizational processes to draw group members to a mutually acceptable accommodated world-view. By studying linkages from the past, including the history of shared understanding, we can see more clearly the long-term interpretive conditions that led to the structuring of the problem in a particular manner. Building these linkages in order to structure a problem involves an extension of technique that is perhaps absent from typical PSMs. It requires the person structuring the problem to create a chain of evidence from which to draw the linkages. To model linkages back to an interested group member means that the evidence used to collate and represent the linked groups requires more evidence than is usually associated with typical problem structuring. It could be that future research looks at modes of linkage analysis involving different methods of data collection. In this case, key stakeholders (negotiators, diplomats, ambassadors) were interviewed and issues were mapped according to linkage type. This was an onerous process, and it is one that requires further investigation if it is to be useful in mapping large-scale problem situations. 


\section{Consecutive-Future Linkage: Present to Future}

Perceptions of the future can be used to influence the present-sometimes strategically. For example, when it was known publicly that Australia and the United States would also negotiate a trade treaty in the later stages of SAFTA telecommunications negotiations, a Singaporean negotiator confronted Australian resistance: 'You [Australia] are saying that you are not prepared to accept such an outcome now, but you will certainly accept this outcome next year when you negotiate with the US - they will give you a bloody nose on this issue. What is the point? Why not concede to Singapore now rather than after you give in to the US next year?’ In another SAFTA example involving intellectual property, one chief negotiator pointed out to the other chief negotiator that SAFTA negotiations should not devote too much time to intellectual property, as Singapore and Australian intellectual property laws would be harmonized through Australia’s negotiations with the United States. The first example demonstrates the strategic use of the future to try to persuade in a current negotiation. The second demonstrates how the perceived future can be used to make present negotiations more efficient. Both techniques can usefully be applied in other settings. Figure 5 illustrates the former example.

Insert Figure 5 about here

Group members within a problem-structuring method or process have a past and present and each exist as an important context that supports the process or intervention in a very tangible manner. In addition, group members also have a perceived future that has some relevance or relationship to the problem under consideration. A PSM intervention might determine how past events or present external events might shape a problem-structuring process, but real investigative work is required to identify how the perceived future of 
specific key group members might shape the problem structure and hence the outcome. Past and present are tangible, and can be documented, but the perceived future of key group members can exist as a vague and intangible force operating on how a problem is structured. To ignore such realities is to risk misunderstanding the key forces shaping a problem structure. On the other hand, to quantify such forces may be equally challenging, as the perceived future can be vague and even perceived in an unrealistic manner.

More often than drawing the future into present negotiations, present negotiations are often used to gain control over some perceived future negotiation or group process. 'Precedent building' — a significant but unexplored area of study —is one important technique for gaining control over the future. Precedents negotiated today can be useful in gaining or losing control in some future negotiation. Such is the importance of avoiding what is perceived as a 'bad precedent' and building what is perceived as a 'good precedent'. One example involves the Australian Pharmaceutical Benefits Scheme (PBS)—a government program that subsidizes the cost of medication for Australian citizens. The primary motivation of the US team to dismantle or at least weaken the Australian PBS was not because the Australian market was so valuable to US industry—it is a fairly small marketbut because the United States would like to dismantle similar programs in Europe that are very valuable to US industry. A precedent in the Australian market would support the United States in its future efforts, so the precedent set by AUSFTA with regard to the PBS carries much more weight than the size of the Australian market suggests.

Insert Figure 6 about here

As noted above, precedent-setting gives those who gain the first interpretation of a problem a form of strategic utility. There has not been much research conducted from the 
point of view of how powerful group members influence and shape outcomes of problem structuring through strategic utility. In this case, we can see that one group member seeks to create a platform to gain a strategic advantage in future group processes or negotiations so that future negotiating partners or future group members are more likely to interpret a problem from a preferred or 'framed' perspective.

The way a problem is framed influences how the other parties react to the problem. This problem now becomes the framework for subsequent interpretations and negotiations. In this case, we see a 'framing effect': one group member creates the interpretation for others that in turn causes them to see the problem through a certain interpretative lens, leading to a certain structure. This creates distinctions with regard to where the boundary of the problem actually lies. It is interesting to note that very little research has been done on how a PSM might be susceptible to framing effects. Second, this initial framing of the issue by prior parties gives these parties an advantage. In this way, a group member uses a precedent to influence the outcome of future problem-structuring activities.

When one group member has the benefit of time and knowledge to use consecutive linkages, this knowledge gives that group member strategic utility to structure the problem to their preferred frame. The strategic utility of previous problem structuring becomes the template or framing effect upon which subsequent problem structuring is drawn. It is interesting to note that strategic utility and framing have not been studied in depth in the PSM literature. We believe that OR can benefit from this approach, creating more relevant research for those in the policy and strategic space.

In this case, we also see an important aspect of problem structuring that is absent from the literature: future expectations play a role in structuring problems. Ledington and Ledington (1999) argue that actors have expectations and desires that they wish to take from a problem-structuring exercise. The matrices they use point towards the same findings we 
have here: that in structuring problems, actors have desires and expectations. We add the idea that the future plays a role in expectations, and this can be used strategically to produce a framing effect on problem structuring to control outcomes in the future. It also points towards the idea that if an actor knows what is coming in the future it will impact on how they structure problems in the present. This temporal idea of problem structuring leads to some interesting concepts of how people perceive the future, and how it shapes present-day problem structuring. In the next section, we summarize these and offer directions for future research.

\section{Conclusion}

To begin to structure a problem, we need to look at how different sets of actors or group members are connected. First, do consecutive-past linkages have influence on problem structuring within a consensus-formation process occurring in the present? Regardless of how a problem is structured - through independent group processes or through intervention/facilitation—might past-linkages have some role in determining group process? In this article, we are able to explain differences in US behaviour based on prior linkages being absent with Singapore and present with Australia. Such differences explain reports of collaboration in Singapore and reports of competitive bargaining in Australia.

Moreover, the processes of resistance, learning and acceptance are not well understood within soft OR, but is highly significant to the establishment of group progress, regardless of the way in which a problem is structured. We are able to use consecutive-past linkage theory to explain Australian behaviour in creating trade rule through Australia’s interaction first with Singapore, then the United States and finally New Zealand. Is it possible that linkage theory can provide understanding and/or assist an invention/facilitation to more effectively manage group process in a PSM? 
Second, do consecutive-future linkages have some kind of influence on problem structuring exercises occurring in the present? Is it possible to draw the expected future into the present to influence a group process strategically? Singapore's behaviour with Australia demonstrates such insight when Singapore sought to use future United States-Australia negotiations to influence telecommunications decisions and intellectual property decisions. It is clear that expectations of group member future can be utilised to shape perceptions of a problem structure. Group members can do this to each other, as can an intervention/facilitation-driven process.

Third, can we use present problem structuring methods to try to understand how a problem will be framed in some future problem-structuring exercise? We demonstrate how the United States sought to establish a 'good' precedent by seeking to dismantle an Australian national health benefit program. In this example there are attempts to create a precedent, but we should be mindful that in many problem-structuring exercises past precedents exist that serve as powerful shapers and framers of a specific problem. Here we are reminded that group members and/or intervention/facilitation processes in PSM might look more carefully at how a precedent was created and the 'legitimacy' of a particular precedent, as precedent construction should play some role in determining legitimacy.

As our findings demonstrate, we are able to see connections between how actors influence outcomes of events by how they saw the issues. Temporal 'forces' shape and can be used to shape how actors frame problems, both from a political and a human activity point of view. This study demonstrates how linkage theory could be useful in incorporating the past and the future in the application of problem-structuring methodologies. In particular, it shows the analytical quality of a linkage and the human politicking and organizing that transcends as powerful actors structure big-picture, long-term problems. 
The challenge of applying linkage theory in a problem structuring intervention is very different from the challenge of studying linkage theory in an academic context. Our Case Methodology section provides a step-by-step approach for conducting academic research to support the development of linkage theory. Actual application of linkage theory is much less difficult. In a problem structuring intervention the practitioner will certainly have an understanding of the relevant context, which is an understanding of a particular environment at a systems-level. Such understanding will be grounded in the history of that system - its values and norms, opportunities and constraints, preferred processes and methods and how this evolved over time. This understanding will establish a foundation for examining potential or real consecutive-past linkages.

However, key players within a system will have their own unique background and so the practitioner may wish to conduct a discussion with these key players to identify potential or real linkages. Embedded in this process may be the possibility that key players have a potential or real conflict of interest and so the practitioner will need to approach these linkages carefully. Many ethical and even legal implications exist here that are too complication to explore but are being identified as areas that deserve special consideration in a problem structuring intervention. Generally, consecutive-past linkages of key players will not presented such complications although identification of such linkages will enrich the practitioners understanding of the problem structuring environment.

Consecutive-future linkages move into the realm of subjectivity, which is grounded in perception. As noted previously the further we move into our understanding of the future the greater the degree of subjectivity. The practitioner will have their own perceived future or perhaps several potential futures with some being more desirable than others. Everyone engaged in a problem structuring exercise will also have a perceived future. 
For example, when Australia first engaged Singapore in negotiations there was no firm agreement that a future negotiation over similar issues would be negotiated between the U.S. and Australia but it was one potential future that was embedded in the minds of the Australian Prime Minister, the Australian Trade Minister and the Australian Ambassador to the U.S. This potential future became more realistic as the U.S. and Australia eventually announced that a trade negotiation was planned. Organisations and the key players within those organisations have a preferred future. What is that future and how might it impact on a current problem structuring intervention? This is the critical question that the practitioner seeks to answer when engaging in a problem structuring intervention.

In the final section, we demonstrate how linkage theory can expand into four key areas for PSM research.

\section{Directions for Future Research}

This first examination of linkage theory and problem structuring suggests that linkage theory could be a useful theoretical framework for adding a temporal quality in structuring larger problems. Three key areas require development. First, a modelling toolkit (akin to systems modelling) that can successfully explain linkages of a temporal nature that do not yet exist. The PSM literature has tools like conceptual mapping, cognitive maps, SODA and so forth. There needs to be an accompanying methodology and set of conceptual/visualization tools that could be useful for structuring the problem situation from a temporal perspective through linkage theory. Most PSMs have this feature, and so it would be useful to develop a toolkit as a supplementary process to existing PSMs. Future research will need to examine the relationship between a temporal framework and a PMS interventionist perspective.

Second, a key question arising from this research is that there are no clear guidelines on how such a method could be applied in a contemporary PSM context. This paper suggests 
that there are temporally framed issues that require attention. A question for future research is how might one integrate such issues with a consistent analytic framework that yields meaningful results. Attempts have been made in Soft OR to account for a temporal perspective, but how does the analyst/modeller recognise the relevance of past events or perceived future events?

We suggest that the analyst modeller might be more aware of how the context evolved through interviews with people in the problem situation. As such, this would involve knowing what the political realities are and analysing this in more detail. Returning again to the use of PSMs in practice, combining a regular methodology with a critical exploration of existing boundaries (such as Critical Systems Heuristics - see Ulrich 2003) covers the need to comprehend the boundary of the problem but it still doesn't show how the event in question frames the future. We suggest that initially the analyst/modeller use a series of questions and interviews to determine the temporal effect of decisions. Asking questions such as, 'What led to this situation' would start to reveal the nascent political realities. In short, there are many ways a PSM modeller/analyst can use these ideas to enhance the problem structuring exercise. We are suggesting that a temporally-focused framework would assist analyst/modellers.

Third,, there is no evidence that linkage theory as it is applied to PSM will work outside of international relations and international negotiations. A question for future researchers is: Would a temporal approach be useful in environments for strategy making or community OR, for example? This question could provide a useful framework for understanding actor relationships prior to an intervention or even during a SODA exercise, for example. Future research should investigate ways of exploring these concerns. We believe that further research into linkage theory will be helpful for understanding temporal effects on problem structuring. 
Fourth, future research could use other linkages that are not mentioned here, but are developed in other literatures. Goodman’s (2000) or Crump’s (2011) structural/multi-level linkage offers a couple of example. It could be useful to develop these structural linkages to explain how some wicked organizational problems have different perceptual levels (as noted earlier in this article), at least according to the manner in which actors perceive utility. This would take the form of using multi-methodology to link separate PSMs together through linked activities to understand how structure in each organization influences how concerns are addressed. We argue that by applying linkage theory to the multi-tiered environment, a useful tool for problem structuring in larger and more complex environments could ensue. In effect, this would help soft OR tools to develop into broader, richer and more complicated political arenas. 


\section{References}

Ackermann, F, Eden, C 2011a. Making Strategy: Mapping Out Strategic Success. 2nd ed. Sage: London.

Ackermann, F, Eden, C. 2011b. Negotiation in strategy making teams: group support systems and the process of cognitive change. Group Decision and Negotiation 20: 293-314.

Ancona, DG, Okhuysen, GA, Perlow, LA 2001. Taking time to integrate temporal research. Academy of Management Review 26, 512-529.

Axelrod, R. 1984.The evolution of cooperation. New York: Basic Books.

Australia-United States Free Trade Agreement. 2004. http://www.ustr.gov [30 July 2012].

Australian-New Zealand Closer Economic Relations Trade Agreement: instructions and Guidelines. 2009. File No. 2008/040878. Commonwealth Government: Canberra.

Bryant J. 2004. Exploring inter-organisational relationships in the health service: an immersive drama approach. European Journal of Operational Research 152(3): 655666.

Bryant, J. 2007. Drama theory: dispelling the myths. Journal of the Operational Research Society 58: 602-613.

Burt, G. 2011. Towards the integration of system modelling with scenario planning to support strategy: the case of the UK energy industry. Journal of the Operational Research Society 62: 830-839.

Checkland, P. (1985). Achieving “Desirable and Feasible” Change: An Application of Soft Systems Methodology. Journal of the Operational Research Society, 36(9), 821-831.

Checkland, PB. 1999. Soft Systems Methodology: A 30-year Retrospective. John Wiley and Sons: Chichester.

Checkland, PB. 2005. Webs of significance: the work of Geoffrey Vickers. Systems Research and Behavioral Science 22: 285-290.

Conklin, J. 2005. Dialogue Mapping: Building Shared Understandings of Wicked Problems. Wiley: Hoboken, NJ.

Crump, L. 2007. A temporal model of negotiation linkage dynamics. Negotiation Journal 23(2): 117-153.

Crump, L. 2010. Strategically managing negotiation linkage dynamics. Negotiation and Conflict Management Research 3(1): 3-27.

Crump, L. 2011. Negotiation process and negotiation context. International Negotiation 16(2): 197-227. 
Cushman, M, Franco, LA, Rosenhead, J. 2006. Facilitating collaboration across organizational boundaries: an exploratory study using problem-structuring methods. Paper presented to Coordination and Cooperation Across Organizational Boundaries conference, Milan, Italy, 20-21 April.

David, PA. 1994. Why are institutions the ‘carriers of history’? Path dependence and the evolution of conventions, organizations and institutions. Structural Change and Economic Dynamics 5: 205-220.

Davis, CL. 2004. International institutions and issue linkage: building support for agricultural trade liberalization. American Political Science Review 98: 153-169.

Drahos, P. 2007. Making and keeping negotiating gains. In Developing Countries and Global Trade Negotiations, L Crump, SJ Maswood (eds). Routledge: London; 97-121.

Druckman, D. 2005. Doing Research: Methods of Inquiry for Conflict Analysis. Sage: London.

Dutton, JE, Dukerich, JM. 2006. The relational foundation of research: an underappreciated dimension of interesting research. Academy of Management Journal 49: 21-26.

Eden, C. 1987. Problem solving or problem finishing? In New Directions in Management Science, MC Jackson, P Keys (eds). Gower: Aldershot; 97-107.

Eden C, Ackerman F. 1998. Making Strategy: The Journey of Strategic Management. Sage: London.

Eden, C, Ackermann, F. 2006. Where next for problem structuring methods? Journal of the Operational Research Society 57: 766-768.

Eisenhardt, KM. 1989. Building theory from case study research. Academy of Management Journal 14: 532-550.

Eisenhardt, KM, Graebner, ME. 2007. Theory building from cases: opportunities and challenges. Academy of Management Journal 50: 25-32.

Fisher, R, Ury, W. 1981. Getting to Yes: Negotiating Agreements Without Giving In. Penguin: New York.

Franco, L. A. 2006. Assessing the impact of problem structuring methods in multiorganizational settings: an empirical investigation. Journal of the Operational Research Society, 58(6), 760-768.

Franco, A., Shaw, D. A., \& Westcombe, M. (2007). Taking problem structuring methods forward. Journal of the Operational Research Society, 58(5), 545-546. 
Franco, LA. 2008. Facilitating collaboration with problem structuring methods: a case of an inter-organizational construction partnership. Group Decision and Negotiation 17(4): 267-286.

Franco, LA. 2009. Problem structuring methods as intervention tools: reflections from their use with multi-organizational teams. Omega 37(1): 193-203.

Franco, LA, Bryant, J, Hindle, G. 2007. Problem structuring and the building and negotiation of strategic agendas. In Strategic Development: Frameworks, Methods and Models, FA O’Brien, RG Dyson (eds). Wiley: Chichester; 87-113.

Friend, J and Hickling, A. 1987. Planning Under Pressure: The Strategic Choice Approach. Pergamon: New York.

Goodman, P. 2000. Missing Organizational Linkages: Tools for Cross-Level Research, Sage: Thousand Oaks, CA.

Gregory, AJ. 2009. Strategic development in higher education: a critical systems perspective. Systems Research and Behavioral Science 25: 605-614.

Houghton, L. 2013. Why can’t we all just accommodate? A soft systems methodology application on disagreeing stakeholders. Systems Research and Behavorial Science 30(4): 430-443.

Howick, S, Ackermann, F, Eden C, Williams T. 2008. Delay and disruption in complex projects. In Complex Systems in Finance and Econometrics, RA Meyers (ed.). Springer Verlag: New York; 116-135.

Huelshoff, MG. 1994. Domestic politics and dynamic issue linkage: a reformulation of integration theory. International Studies Quarterly 38(2): 255-279.

Huaxia, Z. 2010. Soft systems methodology and 'soft' philosophy of science. Systems Research and Behavioral Science 27: 156-170.

Hughes, J., Enlow, SP, Siegel J, and Weiss, J. 2012. From individual competence to organizational capability. In The Psychology of Negotiations in the 21st Century Workplace, BM Goldman and DL Shapiro (eds.), New York: Routledge; 327-361.

Jackson MC. 2001. Critical systems thinking and practice. European Journal of Operational Research 128: 233-244.

Jensen, L. 1963. The postwar disarmament negotiations: a study in American - Soviet bargaining behavior. Ann Arbor, MI: University of Michigan Dissertations.

Keohane, RO and Nye, JS. 1989. Power and interdependence. New York: Harper. 
.Larsen, RK. 2011. Critical systems thinking for the facilitation of conservation planning in Philippine Coastal Management. Systems Research and Behavioral Science 28: 63-76.

Lax, DA, Sebenius, JK. 1986. The manager as negotiator. The Free Press: New York.

Ledington, PWJ, Ledington, J 1999. The problem of comparison in soft systems methodology. Systems Research and Behavioral Science 16(4): 329-339.

Li, C-P. 1993. The effectiveness of sanction linkages: issues and actors. International Studies Quarterly 37: 349-370.

McGinnis, MD. 1986. Issue linkage and the evolution of international cooperation. Journal of Conflict Resolution 30: 141-170.

Midgley, G, Ochia-Rias, A 2004. Community Operational Research: OR and Systems Thinking for Community Development. Springer: New York.

Mingers, J. 2011. Soft OR comes of age but not everywhere. Omega 39(6): 729-741.

Mingers, J, Rosenhead, J 2004. Problem Structuring Methods in Action. John Wiley and Sons: Chichester.

Mitchell, TR, James, LR. 2001. Building better theory: time and the specification of when things happen. Academy of Management Journal 26: 530-547.

Mouzas, S. 2006. Negotiating umbrella agreements. Negotiation Journal 22: 279-301.

Odell, JS. 2000. Negotiating the world economy. Ithaca New York: Cornell University Press.

Odell, JS. 2006. 'Introduction'. In Negotiating Trade: Developing Countries in the WTO and NAFTA, JS Odell (ed.). Cambridge University Press: Cambridge.

Page, SE. 2006. Path dependence. Quarterly Journal of Political Science 1: 87-115.

Pierson, P. 2000. Increasing returns, path dependence, and the study of politics. The American Political Science Review 94: 251-267.

Putnam, RD. 1988. Diplomacy and domestic politics: the logic of two-level games.

International Organization 42: 427-460.

Raiffa, H. 1982. The Art and Science of Negotiation. Belknap Press: Cambridge, MA.

Rosenhead, J. 1989. Rational Analysis for a Problematic World: Structuring Methods for Complexity, Uncertainty and Conflict, John Wiley, UK.

Rosenhead, J. 1996. What's the problem? An introduction to problem structuring methods, Interfaces, 26(6): 117-131.

Rosenhead, J. 2006. The past, present and future of problem structuring methods. Journal of the Operational Research Society 57: 759-765.

Singapore-Australia Free Trade Agreement. 2003. http://www.mti.gov.sg [30 July 2012].

Singapore Competition Act. 2004. http://app.mti.gov.sg/default.asp?id=366 [30 July 2012]. 
Taylor, M. 1976. Anarchy and cooperation. London: Wiley.

Tollison, RD and Willett, WD. 1979. An economic theory of mutually advantageous issue linkages in international negotiations. International Organization 33: 425-449.

United States-Singapore Free Trade Agreement. 2003. http://www.ustr.gov [30 July 2012].

Ulrich, W. 2003. Beyond methodology choice: critical systems thinking as critically systemic discourse. Journal of the Operational Research Society 54: 325-342.

Vennix, JAM. 1999. Group model building: tackling messy problems. System Dynamics Review, 15(4): 379-401.

Vergne, JP and Durand, R. 2010. The missing link between theory and empirics of path dependence: Conceptual clarification, testability issue, and methodological implications. Journal of Management Studies 47: 736-759.

Yin, RK. 1989. Case Study Research: Design and Methods (rev. ed.). Sage: Newbury Park, CA. 


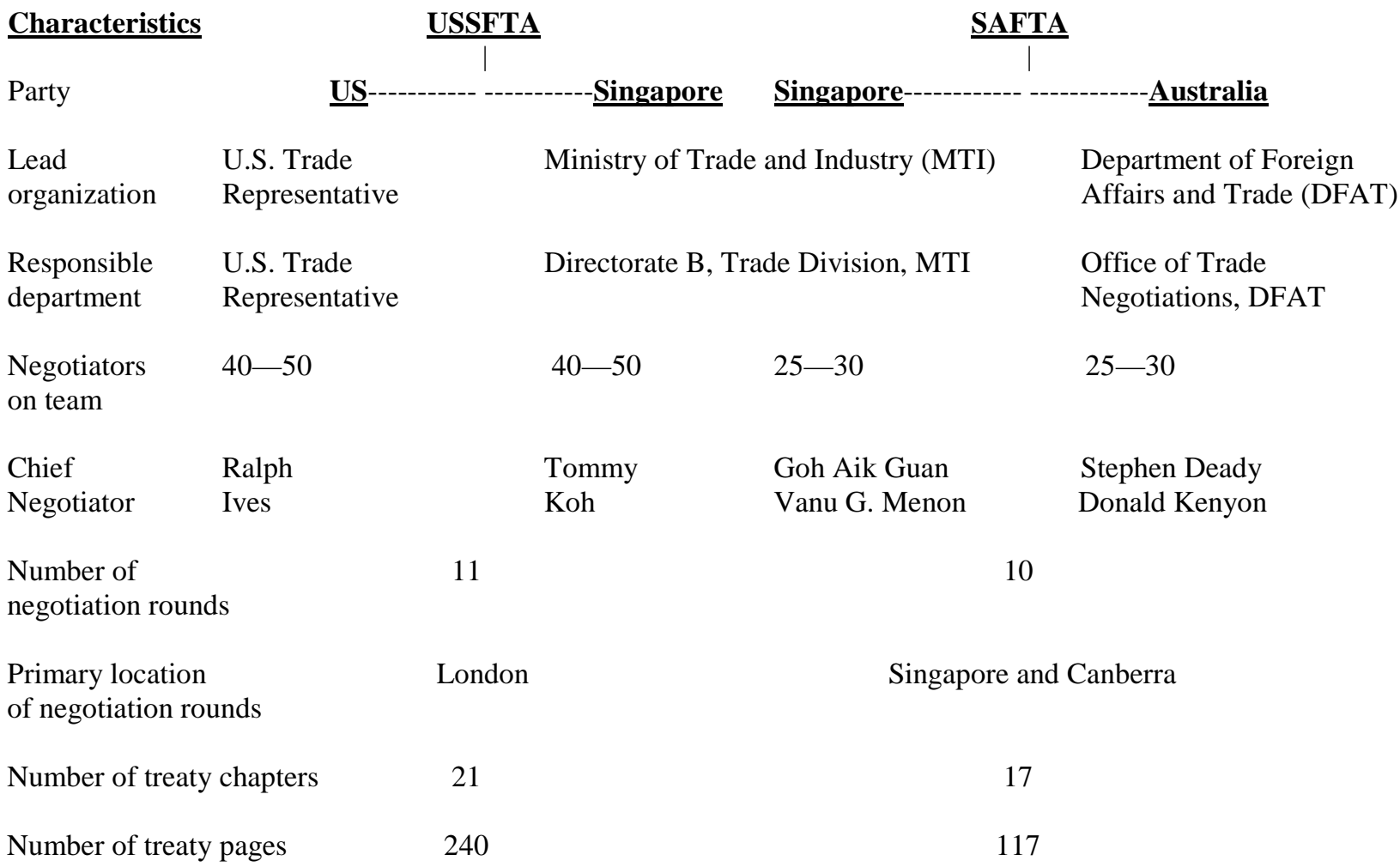

\section{Characteristics}

\section{AUSFTA}

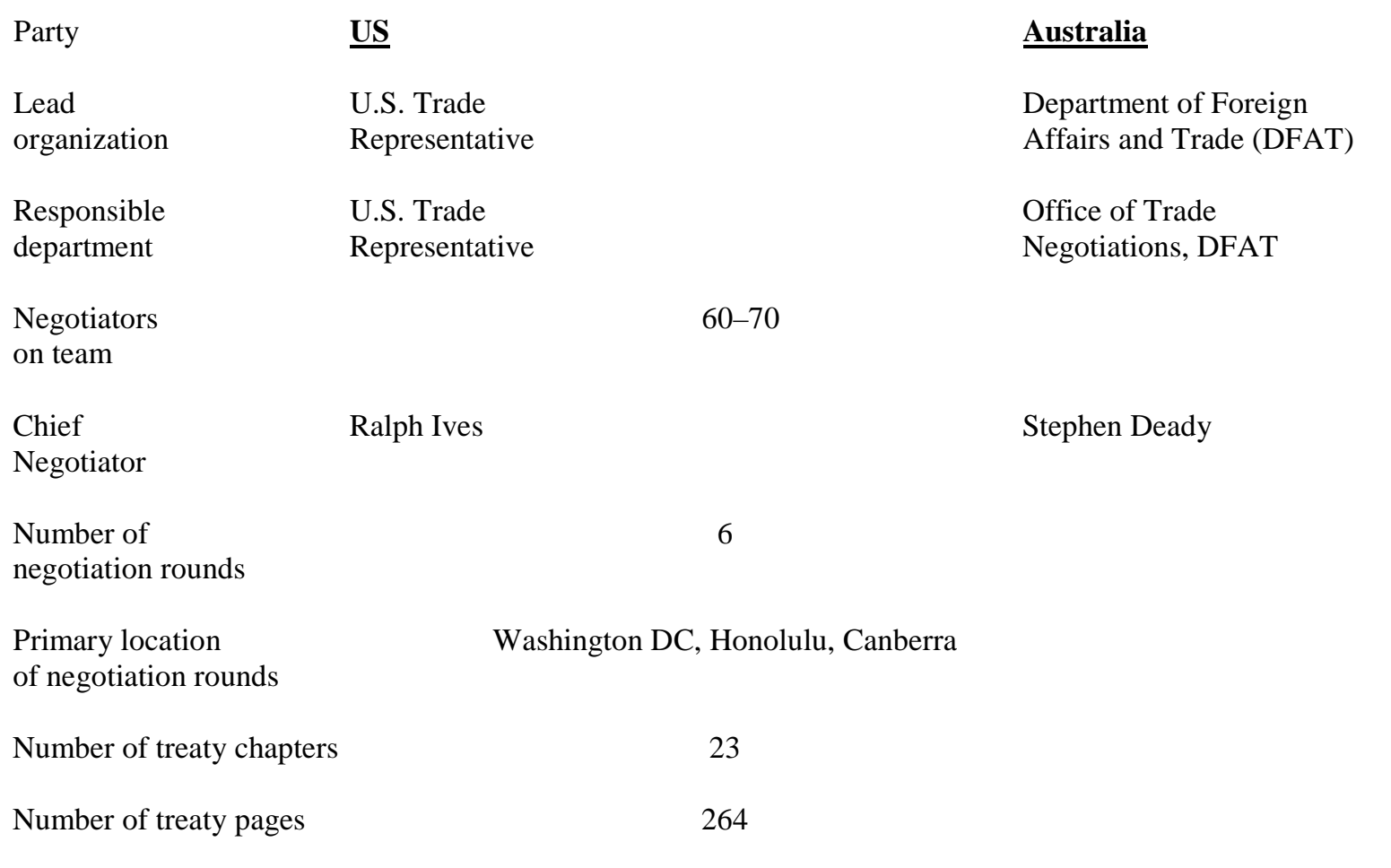




\begin{tabular}{|c|c|c|c|c|}
\hline \multicolumn{5}{|c|}{ Singapore-Australia: SAFTA Treaty - 10 Rounds } \\
\hline $11 / 00$ & $2 / 01$ & 8/01-2/02 & $10 / 02$ & $2 / 03$ \\
\hline & & (Hiatus) & Substantive & Treaty \\
\hline Negot & on Bę & & Conclusion & Signed \\
\hline
\end{tabular}

US-Singapore: USSFTA Treaty - 11 Rounds

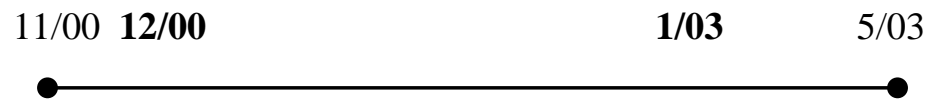

Intention Announced Substantive Treaty

\& Negotiation Begins Conclusion Signed

Australia-US: AUSFTA Treaty - 6 Rounds

\begin{tabular}{llll}
$11 / 02$ & $\mathbf{3 / 0 3}$ & $\mathbf{2 / 0 4}$ & $5 / 04$ \\
\hdashline & & \\
Intention Announced & Substantive & Treaty \\
\& Negotiation Begins & Conclusion & Signed
\end{tabular}

Figure 1. Negotiation Process: SAFTA, USSFTA and AUSFT

Consecutive -Future Linkage

SAFTA
USSFTA
(Present:

Consecutive -Past Linkage

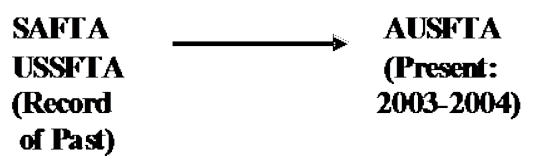

Figure 2. Consecutive Linkage Structure: SAFTA, USSFTA and AUSF 


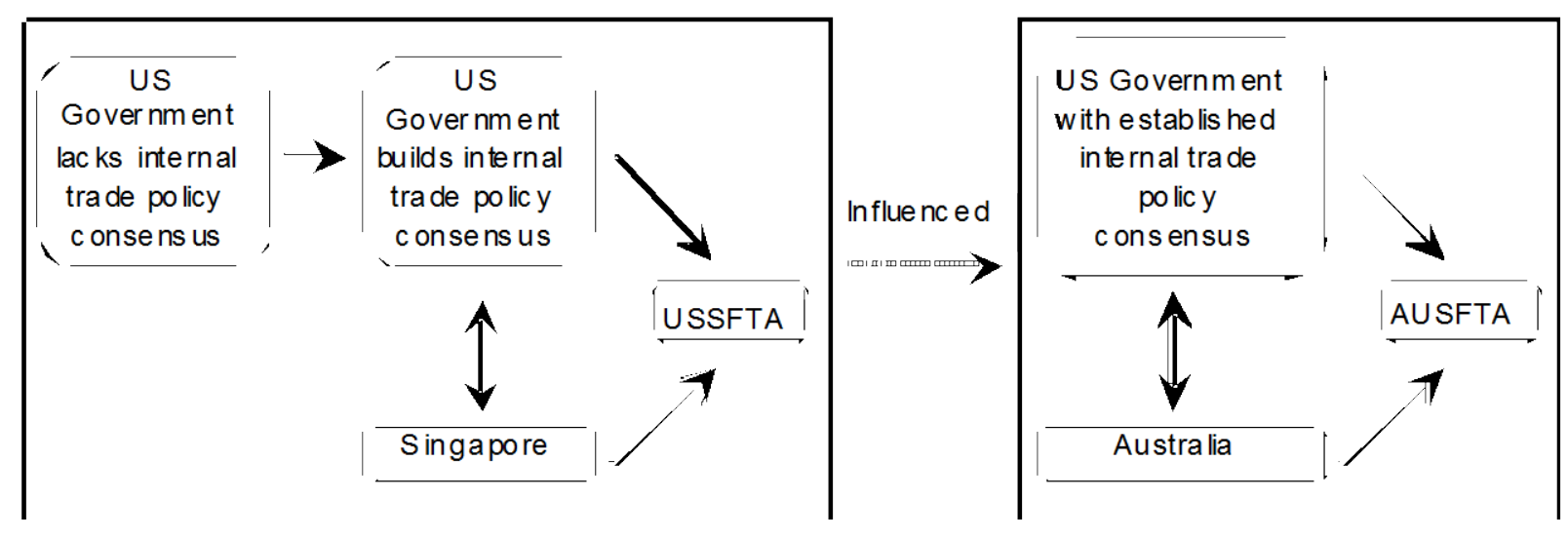

Figure 3: Consecutive linkage-problem formulation, structure and strategy

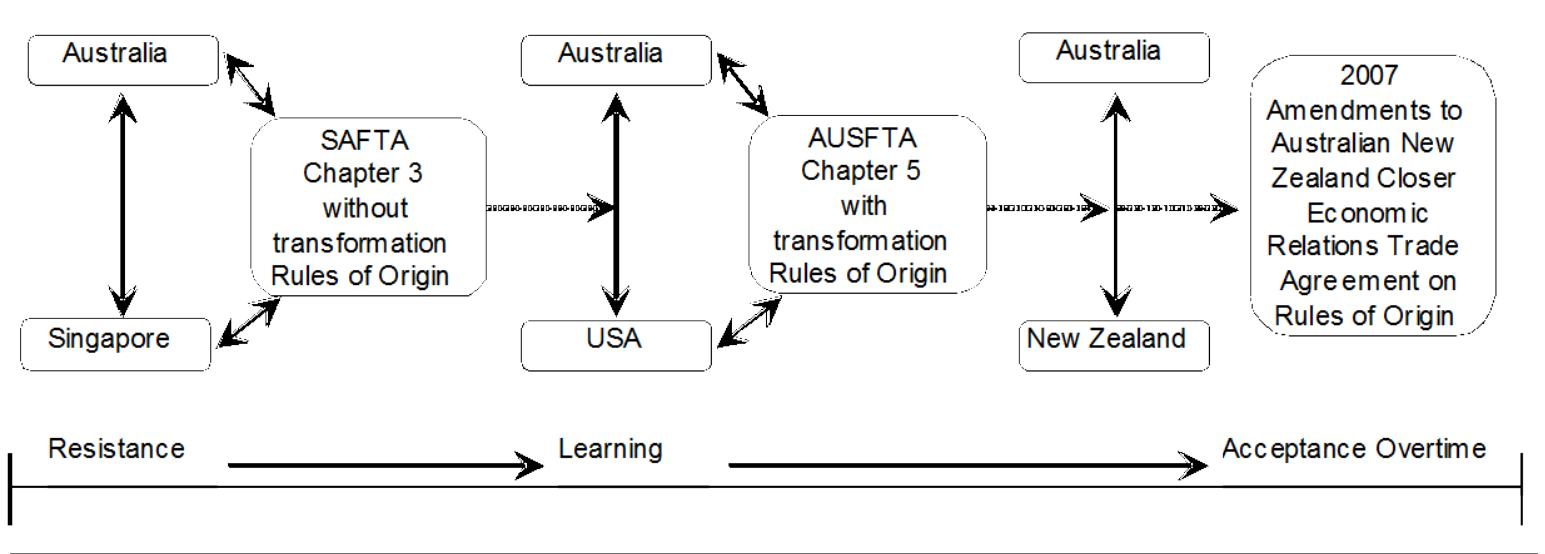

Figure 4: Consecutive linkage over time-resistance learning and acceptance 


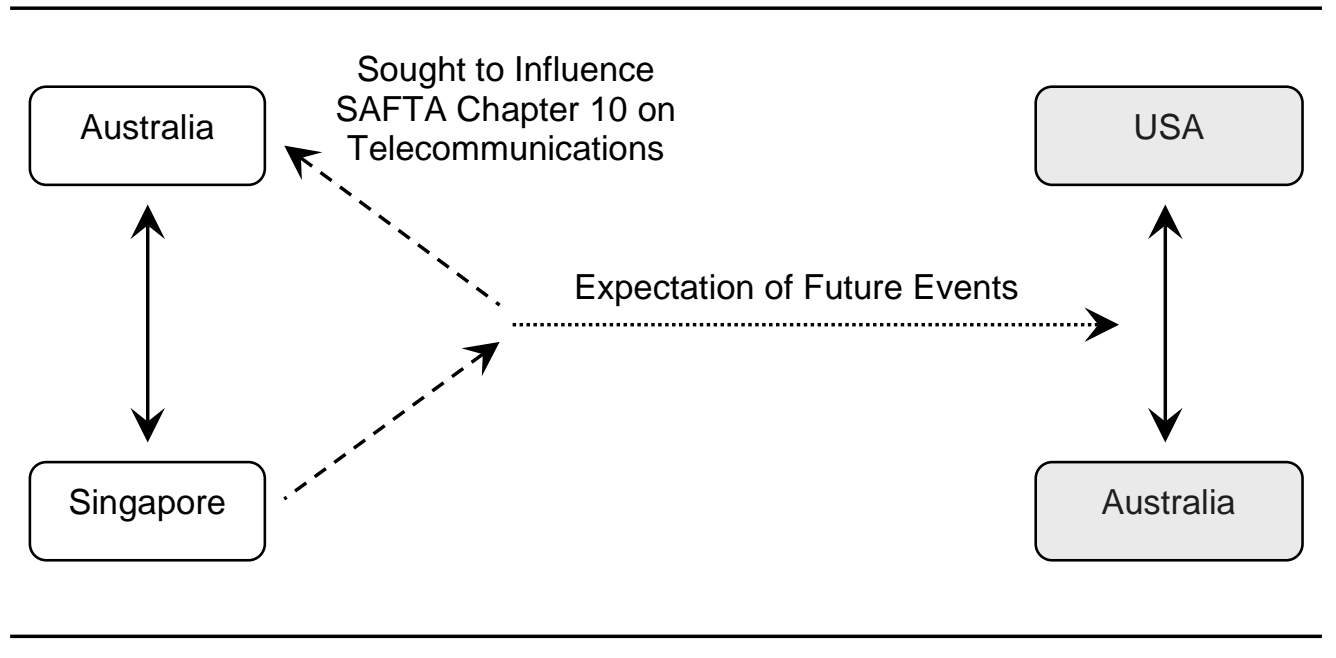

Figure 5: Consecutive linkage—use of expected future to influence present

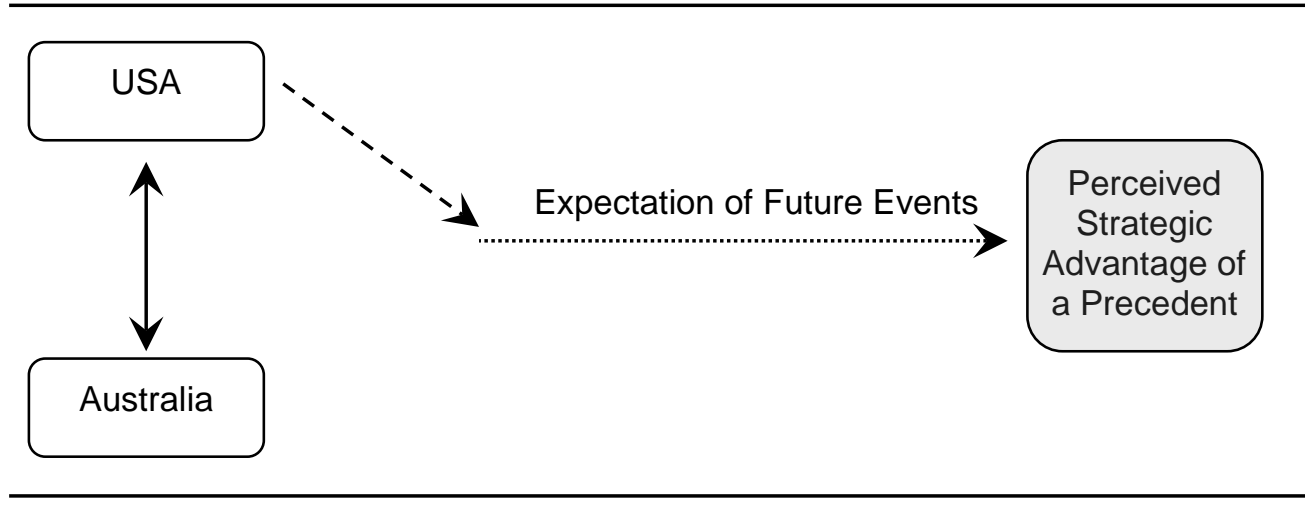

Figure 6: Consecutive linkage—creating precedent for strategic advantage 